\title{
Do dialogismo aos sentidos da dupla autoria nos making ofs documentários
}

\author{
Patrícia de Oliveira luva \\ Doutorado; Universidade Federal de Santa Catarina, \\ Florianópolis, SC, Brasil. \\ patiuva@gmail.com
}

\section{Resumo}

A proposta deste trabalho discute o encontro entre as instâncias diretivas autorais na expressão audiovisual do making of documentário. Tomamos como horizonte teórico a construção social da autoria proposta por Pierre Bourdieu (1996a, 2013) e as noções de posicionamento e dialogismo trabalhadas por Bakhtin (2006), a fim de explicitar caminhos alternativos para as teorias do autor no cinema. Partindo de uma relação dialógica com o filme e seu respectivo auteur, analisamos o discurso dos making ofs documentários na configuração do espaço autoral dos respectivos diretores, Les Blank e Charles de Lauzirika, cujos enunciados manifestam sentidos de uma dupla autoria: voyeurexibicionista e flâneur-dândi.

\section{Palavras-chave}

Autoria. Making of documentário. Campo. Dialogismo. Discurso.

\section{Introdução}

A proposta deste artigo dá continuidade ao trabalho intitulado "Atrás e além das câmeras: proposições inciais para o campo do making of ${ }^{\prime 1}$, no sentido de avançar problematizações que o objeto da pesquisa, os making ofs documentários (MDocs), enquanto produtos extrafílmicos presentes em DVD's/BD's colecionáveis, suscitam no âmbito da produção e da pesquisa em audiovisual. A perspectiva deste trabalho contempla reflexões que buscam dialogar com a Teoria dos Cineastas (CUNHA, 2017) sob dois aspectos: 1 IUVA, Patricia de O.; ROSSINI, Miriam de Souza. Artigo publicado em Revista Significação, São Paulo, v. 45, n. 49, p. 76-95, jan abr. 2018. 
Do dialogismo aos sentidos da dupla autoria nos making ofs documentários

(1) novos caminhos para as teorias do autor ao levar em consideração audiovisuais extrafílmicos; (2) deslocamentos de um pensamento autoral centrado numa única figura criadora, para relações dialógicas que manifestam sentidos de uma dupla autoria.

Assim, o estudo recai sobre a dimensão da relação que ocorre no nível da autoria, uma vez que temos como ponto de partida a natureza relacional (e metatextual) dos making ofs documentários com o filme e, portanto, a instauração de um processo dialógico entre as instâncias diretivas. Assumo destarte a diferenciação entre o diretor do making of e o diretor auteur do filme por dois motivos: (1) pela posição que os diretores auteurs dos filmes ocupam no campo do cinema ficcional, já legitimados e reconhecidos; (2) e também como uma escolha metodológica a fim de facilitar o/a leitor (a), situando o/a mesmo (a) de forma clara e diferenciada para saber quando estivermos falando da autoria do making of e da autoria do filme. Compreendo o espaço autoral do diretor do Mdoc enquanto uma construção social (BOURDIEU, 1996b) constituída por um dado ponto de vista - definindo um modo de enunciar o outro (o filme e seu diretor auteur). Ou seja, estamos diante de um processo que localiza a construção social da autoria para, posteriormente, analisar semioticamente como se dá a relação desse encontro entre as instâncias diretivas autorais a partir dos enunciados dos making ofs documentários, tomando como horizonte teórico a noção de dialogismo proposto por Mikhail Bakhtin (2006). Assim,

Diríamos que a configuração espaço-temporal que tem lugar na arena discursiva é tão elementar quanto fundante do ato dialógico como evento, fornecendo a Bakhtin elementos a partir dos quais ele formula a lei do posicionamento que o levou a entender tudo o que é dito como determinação rigorosa do lugar de onde se diz. Somente o posicionamento permite falar em determinação e relatividade na enunciação discursiva. Todas as visões são relativizadas/determinadas pelo posicionamento: um indivíduo sempre vê o que está fora do campo de visão de um outro [...] (MACHADO, 2007, p. 194).

Em outras palavras, do mesmo modo que o making of olha ao filme e seu diretor auteur, ambos o olham de volta. 0 esforço teórico-metodológico faz-se no sentido de articular a unidade espaço-temporal do mundo dos signos - da linguagem dos making ofs documentários - e suas determinações, bem como relativizações, com as construções sociais da autoria no campo do cinema e do making of. Ora, os posicionamentos sociais dos autores de um campo influenciam o manancial signíco operado, ou seja, uma série de sentidos colocam-se em disputa nos enunciados e modos de constituição dessas relações. 
Nesse ato dialógico, o MDoc constitui, em diferentes níveis, uma enunciação discursiva acerca do filme, sob o qual se entrelaçam sentidos, variações de pontos de vista dos agentes e processos produtivos, memórias de uma dada experiência e condições históricas de sua possibilidade. Pelo viés bakhtiniano, aquilo do que os MDocs falam é apenas o conteúdo do discurso, mas esse discurso é mais do que simplesmente seu tema. Ora,

Toda a essência da apreensão apreciativa da enunciação de outrem, tudo o que pode ser ideologicamente significativo tem sua expressão no discurso interior. Aquele que apreende a enunciação de outrem não é um ser mudo, privado da palavra, mas ao contrário, um ser cheio de palavras interiores. (BAKHTIN, 2006, p. 151)

A abordagem metodológica opera a análise de um fenômeno cultural - o Mdoc - com viés semiótico e sociológico, ao mesmo tempo em que aponta para uma reflexão que considera as relações intersubjetivas imbricadas no ato dialógico da produção discursiva. Entendo, portanto, que o modo como o diretor do making of constrói seu olhar está diretamente relacionado com o modo como o auteur do filme se deixa olhar nessa relação. Isto é, o sujeito da câmera tem sua ação modulada pela forma como o sujeito que se coloca para a câmera se autorrepresenta. 0 diretor auteur do filme se constitui enquanto sujeito para a câmera, visto que ele se confronta com sua própria história no fazer de um determinado filme; o diretor do making of se apresenta enquanto sujeito da câmera, cujo olhar e voz inscritos na montagem das cenas denotam os limites das suas possibilidades, as quais dizem respeito tanto a sua posição social no campo quanto ao princípio da extraposição que orientam os sentidos.

0 princípio da extraposição garante a interação entre relatividade e a determinação; além disso, permite operações particulares no mundo dos signos. [...] Podemos, agora, ampliar nosso conceito: determinar é especificar segundo a visão que se constitui a partir de um ponto de vista do campo da visão do outro. Extraposição, especificação e determinação eis as chaves para se entender o ato dialógico como um evento determinado pela lei do posicionamento, mas relativizado pelas visões que nele, e a partir dele, são projetadas. (MACHADO, 2007, p. 196)

Desse encontro, ou melhor, deste ato dialógico, vislumbro dois tipos de relação projetadas sobre a instância da autoria: voyeurismo-exibicionismo e flâneurie-dandismo. A fim de dar conta dos procedimentos analíticos dessas relações, o corpus se constitui da 
Do dialogismo aos sentidos da dupla autoria nos making ofs documentários

seguinte forma: Burden of Dreams (direção de Les Blank, lançamento no ano de 1982) making of do filme Fitzcarraldo (direção de Werner Herzog, lançamento no ano de 1982); Dangerous Days: making Blade Runner (direção de Charles de Lauzirika, lançamento no ano de 2007) - making of do filme Blade Runner (direção de Ridley Scott, lançamento no ano de 1982).

Dangerous Days: making Blade Runner foi lançado em 2007 com a Edição Especial em DVD/ BD do filme Blade Runner, a qual foi premiada no Saturn Awards na categoria Best DVD Special Edition Release. Dentre as muitas informações extras contempladas nos diferentes boxes lançados, está o making of documentário dirigido e produzido por Charles de Lauzirika. Nascido nos Estados Unidos, Lauzirika cursou a Faculdade de Cinema da Universidade do Sul da Califórnia (USC). Durante a faculdade, trabalhou concomitantemente em projetos de inúmeras companhias cinematográficas, como Lucasfilm Ltd., Lightstorm Entertainment, Warner Bros. eSilver Pictures. Ainda durante esse período, Lauzirika começou a estagiar na Scott Free, empresa de Ridley Scott e Tony Scott. Entre 1997 e 1998, quando a tecnologia do DVD estava começando a se impor no mercado cinematográfico, Lauzirika soube que a Fox estava interessada em lançar um conjunto dos filmes da franquia de Alien, o que se tornou The Alien Legacy set. Nas palavras de Lauzirika (2016):

E aconteceu de eu mencionar a Ridley que esses DVDs iam ser realmente um grande formato, e que talvez ele devesse aproveitar a circunstância, analisar e se inteirar do assunto e em cima disso, que por favor fizesse esse primeiro set de Alien o melhor que ele pudesse. Eu dei-lhe um briefing completo sobre o formato do DVD e todo o seu potencial e, antes que ele fosse se encontrar com a Fox, ele basicamente se virou para mim e perguntou: “isso é algo do qual você pode ser responsável para mim?”; e eu praticamente disse que sim, embarquei na tarefa e foi uma prova de fogo. (LAUZIRIKA, 2016, doc. não paginado, tradução nossa).

Seu primeiro trabalho foi apenas de supervisionar The Alien Legacy set, cujo lançamento em 2001 trouxe um conjunto ainda limitado no sentido de materiais extras. Mais tarde, em 2003, Lauzirika encarregou-se de um novo box set da franquia, intitulada Alien Quadrilogy, no qual pôde produzir e dirigir todo material extra para os quatro filmes integrantes do box. Em 2010, esteve por trás da produção de um novo box para a franquia, Alien Anthology, que trouxe ainda mais materiais inéditos e versões diferentes de alguns making ofs. Lauzirika foi escolhido por Ridley Scott para supervisionar e produzir elaboradas edições especiais em DVD (e, posteriormente, Blu-ray) dos clássicos da filmografia de Ridley. Além do reconhecimento com a Quadrilogia de Alien, outro trabalho 
Do dialogismo aos sentidos da dupla autoria nos making ofs documentários

seu que ganhou destaque entre os fãs e a crítica especializada do campo cinematográfico foi a edição Blade Runner: Ultimate Collector's Edition, lançada em 2007. Ainda que o trabalho dele esteja primordialmente associado com os filmes de Ridley Scott, Charles de Lauzirika também produziu e dirigiu conteúdo para DVD's/BD's de filmes de outros diretores, como David Lynch, Sam Raimi, James Cameron, irmãos Coen, Michael Bay, David Fincher, Robert Rodriguez, Marc Webb, Jean-Pierre Jeunet, Mark Romanek e Tony Scott. Dentre seus projetos não relacionados com Ridley Scott, merece destaque a edição especial de Twin Peaks ${ }^{2}$, lançada em 2007 sob o título Twin Peaks Definitive Gold Box. Vale dizer que a produção dessas edições especiais envolve desde a concepção gráfica dos menus dos discos até a criação e desenvolvimento dos extras, que contam com making ofs, pesquisa de cenas deletadas, vt's promocionais da época, pesquisa de materiais de arquivo das gravações, etc. Além de ser um trabalho de criação, trata-se também de um esforço que envolve muita pesquisa.

Burden of dreams, dirigido por Les Blank e lançado em 1982, foi exibido nos cinemas, em programa de televisão e em festivais de documentário. Sua distribuição, além das telas do cinema e da televisão, teve versões em VHS e DVD. Constituído enquanto um making of documentário bastante autônomo, foi apenas no ano de 2007, que numa edição comemorativa de 25 anos do filme Fiztcarraldo, é lançado juntamente com o filme. 0 caso de Les Blank (1935-2013) é, talvez, um pouco mais complexo do que o de Lauzirika, pois tratase de um cineasta independente cuja distinção e reconhecimento no campo cinematográfico do documentário marca sua trajetória. Nascido em Tampa (Flórida - Estado Unidos), Les Blank estudou Inglês na Universidade de Tulane, em New Orleans. Depois foi para Berkeley, onde gradou-se em cinema. Após a graduação da escola de cinema, realizou inúmeros filmes educacionais e empresariais, a fim de financiar seus projetos pessoais em curtas-metragens. Dois anos após filmar o curta Dizzy Gillespie, de 1964, Les Blank fundou sua produtora: Flower Films. 0 filme que o colocou no mapa dos documentaristas (bem como no universo dos amantes da música) foi The Blues Accordin' to Lightnin' Hopkins (do ano de 1968). Inúmeros cineastas e críticos costumam dizer que Les Blank conseguia filmar coisas que ninguém mais conseguiria: "[...] ele realmente fica perto das pessoas, e você realmente consegue sentir como elas vivem" (LES BLANK, 2013, doc. não paginado, tradução nossa).

Os textos que costumam dar conta da biografia de Les Blank, recorrentemente, enaltecem o modo como o diretor construiu verdadeiros retratos íntimos e poéticos acerca das vidas, da cultura e da música da sociedade americana periférica. Os tópicos de seus

2 Twin Peaks foi uma série de televisão da década de 1990, criada por Mark Frost e David Lynch. Teve duração de duas temporadas. É reconhecida no campo televisivo como um marco na produção seriada. 
Do dialogismo aos sentidos da dupla autoria nos making ofs documentários

filmes incluíram as músicas e a comida de povos mexicanos, havaianos, poloneses, sérvioamericanos; afro-cubanos percussionistas; músicos de blues do Texas; violinistas Apalaches, etc. Um traço relevante de seu trabalho são as parcerias, tendo como característica, portanto, o tom do colaborativismo do cinema independente. Nesse sentido, a relação com Herzog é um tanto curiosa, pois antes de dirigir Burden of Dreams, Les Blank realizou um curtametragem intitulado Werner Herzog Eats His Shoe (1980). Esse curta-metragem é resultado de uma aposta feita entre Herzog e Errol Morris, na qual Herzog declarou que comeria um sapato se Morris um dia terminasse o filme Gates of Heaven (Portais do Céu, 1978). 0 filme segue a jornada de Herzog de sua casa até San Francisco, onde o sapato está sendo preparado por Alice Waters e sua equipe no restaurante Chez Panisse, em Berkley. A relação Les Blank-Herzog quando da realização do MDoc de Fitzcarraldo não era algo novo, portanto. 0 resultado de Burden of Dreams foi tão aclamado pela crítica, que o nome de Les Blank é corriqueiramente associado a esta obra. Sua filmografia, no entanto, é bastante extensa e, entre as décadas de 1970-1990, inúmeras retrospectivas de suas obras foram organizadas em diferentes lugares do mundo.

A partir dessa breve incursão nos objetos de análise, vale ressaltar que, em última instância, trata-se reconhecer de que no escopo da problemática da pesquisa - a noção de dupla autoria -, importam tanto as obras quanto seu contexto produtivo, uma vez que é por meio dessas complexas relações que vislumbro a possibilidade de se desvelarem princípios internos acerca do reconhecimento e funcionamento da autoria nos making ofs documentários.

\section{Apontamentos acerca da construção social da autoria}

O status de autor, conferido ao diretor, é alvo de disputa desde que Truffaut, Bazin e Astruc lançaram a politique des auteurs. Na trajetória do conceito existe uma história própria para o status/noção de autoria, que articula fronteiras com outros campos de produções culturais. Como afirma Bourdieu (1996b), cada campo, embora possuindo sua própria lógica e uma relativa autonomia, é atravessado por clivagens. Há, portanto, uma interpenetração dos campos. No caso da autoria, as lógicas de sua conservação, subversão ou ainda de reprodução remontam à literatura e também à pintura. É necessário considerar que se trata de uma questão em disputa não apenas dentro do campo do cinema (ou do making of), mas em disputa dentro de um campo maior: o artístico.

O caminho trilhado pela noção de autoria está diretamente relacionado com as condições e as estruturas sociais de cada período histórico. De acordo com Wolf (1997), por 
Do dialogismo aos sentidos da dupla autoria nos making ofs documentários

muito tempo a literatura seguiu a tendência dos críticos literários de oferecerem explicações psicoanalíticas sobre a relação autor-obra. Na história da pintura, um dos principais obstáculos é a visão de uma história da arte como uma história dos artistas. Esse centramento no artista como indivíduo criador é reflexo das condições do progresso capitalista industrial da Europa do final do século XIX. Mesmo diante das inúmeras objeções possíveis a essa noção de autoria, o cinema, a fim de alçar um lugar dentro do campo das artes, buscou nesse mito do artista-indivíduo criador o mecanismo da manifestação artística cinematográfica. Importava menos que o cinema fosse uma expressão coletiva e não individual tal como a pintura ou a literatura, pois o relevante nesse jogo implicava na ação de clamar por um autor para a obra cinematográfica, o que instaurava, imediatamente, a discussão da arte do cinema dentro do próprio campo artístico.

As produções de obras culturais e artísticas não deveriam ser encaradas como reflexo de alma ou encarnação de uma ideia platônica, mas resultado de um campo de forças, tal como elucida Bourdieu (1996a). A distribuição de poderes e privilégios entre os diferentes agentes engajados na concorrência, bem como vinculações e pressões de ordem econômica, cultural e simbólica, circunscrevem a atuação dos indivíduos nos diferentes campos pelos quais circulam. Ainda, segundo Bourdieu (2013), os agentes sociais procuram sempre manter ou aumentar o volume do seu capital e, logo, manter ou melhorar sua posição social. Ao considerarmos, por exemplo, o momento da Nova Hollywood (na década de 1970), é perceptível que o deslocamento dos novos diretores, em sua maioria egressos das faculdades de cinema, para a posição de autores foi uma estratégia de investimento cultural e simbólico empreendida pelos próprios agentes do campo, a fim de reproduzir esquemas de apreciação favoráveis às suas propriedades e retomar público espectador para as salas de cinema, assegurando ao cinema hollywoodiano predomínio no mercado. Uma vez consolidados dentro do espaço hollywoodiano, o rótulo autoral conferido, por exemplo, a Steven Spielberg, Francis Ford Coppola, Martin Scorsese, George Lucas e Brian DePalma deve sair em busca de novos instrumentos e estratégias para a reprodução e/ou ruptura dessa nova estrutura. Esse é o mecanismo dinâmico operado no interior dos campos.

Por meio de uma composição da sociedade em diferentes campos que não são excludentes, mas, ao contrário, que se cruzam e provocam interferências entre si, é possível considerarmos o campo do making of e os atravessamentos com outros campos e subcampos. Diante dessa lógica de funcionamento, contemplo os making of documentários enquanto audiovisuais extrafílmicos cujos enunciados reafirmam o diretor auteur do filme, assegurando a perpetuação de uma dada estrutura social e relações de poder. Ao mesmo tempo, porém, tendo em vista uma perspectiva dinâmica do espaço social, passo a 
Do dialogismo aos sentidos da dupla autoria nos making ofs documentários

considerar outra ordem de sentidos que evocam uma renovação da autoria: a instância diretiva do making of.

O campo artístico designa um conjunto de relações sociais que os indivíduos estabelecem entre si e com a cultura no contexto de um processo de transformação da mesma em bem de consumo, o que implica estudar as estruturas, os sentidos e os valores atribuídos às produções culturais tecnológicas. Pode-se dizer que existe uma dinâmica de negociação sígnica e de poder que se estabelece por meio do encontro das instâncias diretivas nos making of documentários: de um lado, aquele que empunha a câmera e/ou ordena a narrativa (o diretor do MDoc) e, de outro lado, aquele que se inscreve enquanto alteridade filmada (e também autorrepresentada) (o auteur do filme ficcional) instaura um mecanismo autoral intersubjetivo, ou seja, a relação eu-outro modula um espaço de dupla autoria. A dimensão do posicionamento de um eu e de um outro, revelada pelo dialogismo bakhtiniano, manifesta um olhar que se autoriza, organiza e distribui formas de enunciar o outro, ou seja, diretores auteurs já reconhecidos que se deixam olhar (da mesma forma que olham e constroem uma autorrepresentação de si) e os diretores dos making ofs em processo de construção de seu espaço autoral.

Pelo viés socio semiótico, não devemos buscar os significados dos bens culturais apenas em suas formas e conteúdos, mas também na maneira como os mesmos permitem o envolvimento da experiência discursiva sob condições determinadas. Para Bakhtin (2006)

A enunciação de outrem pode ser apreendida como uma tomada de posição [...] Mas pode-se também apreender e transmitir de forma analítica a enunciação de outrem enquanto expressão que caracteriza não só o objeto do discurso (que é, de fato, menor) mas ainda o próprio falante. (BAKHTIN, 2006, p. 163-164)

Congregando o pensamento do autor com o de Miriam Hansen (2012), que define o lugar da espectatorialidade do cinema clássico enquanto uma formação histórica particular numa espécie de "voyeurismo privatizado, isolante e unilateral" (HANSEN, 2012, p. 240), proponho compreender a dimensão dialógica na concretude enunciativa dos MDocs. Desse modo, é válida a concepção de Hansen (2012) para refletirmos sobre a experiência dos diretores dos MDocs, os quais assistem, experienciam todo o processo de produção da obra fílmica numa condição, num espaço de alguém privilegiado, que pode "espiar" a descortinização da criação numa espécie de fascínio (um voyeur) ou pode vivenciar a observação com o espírito de curiosidade, de incursão, de quem vagueia, perambula pela 
Do dialogismo aos sentidos da dupla autoria nos making ofs documentários

experiência registrando aquilo que o estimula (um flâneur). Pensando nos termos de variações de posicionamento discursivo dos diretores dos Mdocs, uma autoria voyeurística constrói (da mesma forma que é construída por) um auteur exibicionista, emaranhando uma trama, um jogo do ver e ser visto calcado no desejo pelo outro e na aparição do eu. Por outro lado, o contraponto dessa relação é dado a ver por uma flâneurie e um auteurismo dândi, os quais representam uma versão que busca se afirmar através da resistência contra as regularidades já instituídas, abrindo espaço para uma travessia discursiva que abriga os autores dos making ofs.

Por exemplo, a relação "Lauzirika-Scott" e "Les Blank-Herzog" ${ }^{3}$, envolta numa estratégia de investimento econômico ${ }^{4}$ nos termos de Bourdieu (2013), permite considerar que a oportunidade de assinarem a direção desses MDocs, atribui a esses diretores (Charles de Lauzirika e Les Blank) um direito de acesso, um discurso autorizado. Ou melhor, atribuise a eles um determinado status de forma a instaurar um novo espaço de ocupação autoral. Tem-se um movimento fluido da autoria: a fim de reproduzir a condição autoral de Ridley Scott e Werner Herzog, os enunciados dos MDocs introduzem um novo elemento: o seu próprio diretor autor, na condição de alguém que olha e (re)constrói a trajetória e a obra de outrem. 0 que se observa é uma dinâmica ligada ao jogo dos participantes do espaço social, em que as relações, a trajetória e a construção dos discursos devem ser privilegiados a fim de uma compreensão mais profunda do funcionamento da noção de autoria no campo do making of. 0 making of documentário e suas formações discursivas nos obrigam a constituir outro filme, cuja autoria já é outra.

A possibilidade de revelação dessa autoria não percebida evoca a potencialidade dos making ofs documentários para a teoria dos cineastas e outras proposições para as teorias do autor. Identifico, portanto, diferentes formas de posicionamentos intersubjetivos de uma dada experiência que redefinem a maneira de percorrer o espaço de ocupação autoral na produção de MDocs. A autoria aqui está associada ao reconhecimento de um modo de operação dos enunciados do making of - na sua relação com o filme-, o qual está circunscrito por condições específicas do campo e da posição que o diretor ocupa dentro do mesmo nessa relação.

3 Charles de Lauzirika é o diretor do making of documentário Dangerous days: making Blade Runner. Ridley Scott é o diretor do filme Blade Runner. Les Blank é o diretor do making of documentário Burden of Dreams (acerca do filme Fotzcarraldo) e Werner Herzog é o diretor do filme Fitzcarraldo.

4 Considero aqui a ideia de que se trata de um investimento social que visa instaurar ou manter relações sociais diretamente utilizáveis de modo a transformá-las em obrigações duradouras pela troca de dinheiro, trabalho, tempo. 


\section{Considerações finais: desvelando o espaço da dupla autoria}

De maneira geral, o que observo é que não apenas o nível narrativo dos MDocs, mas também a relação com as imagens produzidas é marcada por uma combinação inteligível que transforma o mundo em discurso. Esse discurso recai, hegemonicamente, sobre a figura dos diretores auteurs, seu papel na criação e produção do filme, sua relação com a equipe, o controle permitido, adquirido e desempenhado, enfim, uma série de aspectos que configuram a instância autoral do filme.

A abordagem que guia este trabalho, no entanto, é que este espaço da autoria configurado pelos MDocs se estabelece a partir de uma relação cuja natureza dialógica institui posicionamentos enunciativos que evocam sentidos de dupla autoria, ultrapassando o nível unívoco do discurso acerca dos diretores auteurs, e nos dá a ver, por conseguinte, os diretores autores responsáveis por essa construção discursiva. Ou seja, buscamos desvelar e apreender a constituição do outro à sombra dos auteurs: dos diretores autores dos making ofs documentários.

Desse modo, a autoria dos diretores dos MDocs está inscrita não somente no trabalho de cada um sobre os enunciados, mas, da mesma forma, é determinada pela sua posição no campo. Aqui, vislumbro uma dimensão bourdieuseana na qual podemos dizer que os enunciados autorais do diretor do making of são reflexos de sua trajetória e posição no campo, o que não significa dizer que na busca por reconhecimento e/ou consagração esta posição não possa ser alterada, diante das potencialidades criativas que venham a se apresentar como virtualidades no interior do campo. Do ponto de vista de Bakhtin (2006).

[...] pode-se afirmar que na composição de quase todo enunciado do homem social - desde a curta réplica do diálogo familiar até as grandes obras verbal-ideológicas (literárias, científicas e outras) - existe, numa forma aberta ou velada, uma parte considerável de palavras significativas de outrem, transmitidas por um ou outro processo. No campo de quase todo enunciado ocorre uma interação tensa e um conflito entre sua palavra e a de outrem, um processo de delimitação ou de esclarecimento dialógico mútuo [...] (BAKHTIN, 2006, p. 153)

No MDoc Dangerous Days: making Blade Runner a narrativa está fortemente associada aos imperativos da organização do fluxo produtivo. A heterogeneidade das imagens reivindica uma abordagem do universo do filme com capacidade de intervenção através da montagem. Um quadro compositivo nos moldes de uma coleção de fragmentos dispersos cuja organização dá a ver um tratamento criativo transmitido por uma força 
Do dialogismo aos sentidos da dupla autoria nos making ofs documentários

persuasiva da representação (NICHOLS, 2005). Dos enunciados das entrevistas ao longo do MDoc, dispersos de acordo com a construção narrativa, é possível identificar correlações e posições assinaláveis que nos permitem perceber a construção discursiva do auteur enquanto aquele que detém controle sobre a obra. As palavras de Ridley Scott durante o making of traduzem essa ideia:

Meu filme, o filme que eu faço, no fim das contas, é meu. Pode ser algo de equipe também. Mas eu levo as críticas. Eu levo os golpes. E provavelmente eu o desenvolvi, etc, etc. Então, sim, é o meu filme. E convido as pessoas a virem fazê-lo. Um diretor é isso. Eu estava absolutamente focado em coordenar a beleza. Plano a plano tinha que ser perfeito. 0 que eu estou esperando de você será muito elevado. Você não vai ser desperdiçado. Eu escolhi você, porque você é realmente bom no que faz e eu vou realmente exigi-lo como um louco. Eu vou conseguir o melhor. (DANGEROUS DAYS, 2007).

Ainda que Ridley Scott fosse um diretor contratado para realização de Blade Runner e não tivesse envolvimento no roteiro do filme, a formação discursiva o constrói para que o percebamos enquanto autor individual, cujas dependências do sistema não influenciam na sua visão para o filme. Dangerous Days exalta não apenas a força e obstinação de Ridley Scott, mas também sua visão artística para o filme. É como se as habilidades de Ridley e sua inventividade prevalecessem sobre as determinações econômicas do sistema. Vale lembrar que Scott ainda não é produtor nesse estágio da carreira. Nesse sentido, o MDoc contribui para a configuração da dimensão autoral que nos remete à figura do auteur cujo controle ultrapassa os limites impostos pelas condições econômicas de produção. A metáfora do status estético (CALDWELL, 2008), a fim de elevar simbolicamente o caráter artístico de filmes gestados no modelo de produção industrial de Hollywood, é reforçado pelos depoimentos dos atores e atrizes, bem como de alguns membros da equipe, que enfatizam o aspecto visionário do diretor e da obra que está sendo realizada.

Por meio de operações de montagem - com função comprobatória e de sustentação do que afirma - que articula entrevistas, vídeos da época da filmagem de Blade Runner e todo tipo de imagem (fotografia still, storyboards, cenas gravadas e não utilizadas no filme, cenas presentes no filme, etc.) capaz de traduzir e/ou evidenciar em certa medida as falas dos depoimentos, o MDoc é responsável pela criação de uma memória de Ridley Scott enquanto auteur. Em inúmeros fragmentos do MDoc somos interpelados por enunciados verbais e visuais que evocam o controle e a centralidade da atuação de Ridley. Isso recai no que Bourdieu (1996a) aponta como "ver enquanto tal", ou seja, lugar próprio do artista, 
Do dialogismo aos sentidos da dupla autoria nos making ofs documentários

daquele que detém o direito de entrada no campo segundo princípio fundador (BOURDIEU, 1996a, p .253).

Ao produzir e dirigir Dangerous Days em 2007, quase 25 anos após a realização de Blade Runner, Charles de Lauzirika se inscreve na própria obra de modo a prestar homenagem ao filme que enuncia e ao seu respectivo diretor auteur. Além de ficar evidente ao longo do MDoc o discurso celebrativo, Lauzirika afirmou em entrevista, quando indagado a respeito de seu trabalho e da sua relação com Ridley Scott, que é disso que se trata a realização de seus making ofs: "[...] para mim, é em última análise, sobre homenagear, certificar-se que o trabalho deles será imortalizado. Não significa que tudo sempre corra bem ou que tudo é sempre um piquenique." (LAUZIRIKA, 2016, n.p., tradução nossa). Isso se deve, em grande parte, ao descompasso da posição dentro dos campos evidenciado pela relação estabelecida com Ridley Scott. 0 reconhecimento de Lauzirika, restrito ao campo do making of não é homólogo ao de Ridley Scott no campo do cinema ficcional. Diante disso, o olhar de Lauzirika está fortemente condicionado pela sua trajetória social, pela posição que ocupa, pelas condições específicas de produção ${ }^{5}$ e também por sua aspiração a integrar o campo do cinema ficcional ${ }^{6}$.

A instauração da narrativa criada por Lauzirika se constitui por um exercício de alteridade - de olhar o outro. Nesse sentido, tem-se que este Outro também olha, e é nesse jogo que ambos se constroem. No caso de Dangerous Days trata-se de uma construção operacionalizada não por uma câmera que percorre o set de filmagem, no tempo de realização do filme, mas por um recurso de perscrutar arquivos, revirar o passado, posicionar a câmera para entrevista anos após as filmagens com intenção de resgatar algo que já foi. Tem-se apropriação de cenas dos filmes para construir o MDoc e conduzir a narrativa de modo a localizar o diretor auteur como elemento central na criação da obra. Desse modo, está preso a uma ideia hegemônica de making of, operando num espaço às sombras, invisível para determinados agentes do campo cinematográfico. Diante disso, o funcionamento da instância diretiva autoral de Charles de Lauzirika opera contornos de voyeurismo. Pensando nos termos de Lacan (1988), o voyeur é o sujeito de uma nova era espetacular, cuja tônica essencial é olhar o Outro.

De acordo com Lacan (1988), “[...] o que ele procura ver, saibam bem disto, é o objeto enquanto ausência. 0 que o voyeur procura e acha é apenas uma sombra, uma sombra detrás da cortina." (LACAN, 1988, p. 173). Situa-se a busca pelo que não se pode ter. Neste caso, o que está fora do alcance de Lauzirika é a posição de auteur associada ao campo do cinema

50 fato de que se trata de um making of realizado quase 25 anos após o lançamento do filme.

6 Aspiração demonstrada com a realização de seu primeiro longa-metragem ficcional Crave, lançado em 2012. 
Do dialogismo aos sentidos da dupla autoria nos making ofs documentários

ficcional. A função-desejo da sua obra é imortalizar a obra do outro. Sobre isso, o autor afirma: "O objeto do desejo é a causa do desejo, e esse objeto causa do desejo é o objeto da pulsão - quer dizer, o objeto em torno do qual gira a pulsão [...]" (LACAN, 1988, p. 229). A pulsão que orienta os MDocs de Lauzirika é a homenagem e celebração do auteur e seu filme, o que evidencia o contorno de um desejo pela ocupação deste lugar. É nessa esfera que se pode contemplar um espaço autoral voyeurístico, o qual, sempre em uma distância segura e autorizada, espia seu objeto de desejo.

Do ponto de vista de uma relação intersubjetiva, é possível afirmar que o voyeur se constitui numa relação que encontra correspondência com o olhar do Outro. Esse Outro é o diretor auteur do filme, que se constrói como olhado e retorna, na forma invertida do voyeur, como exibicionista. Ivo Lucchesi (2000, p.50) salienta que "O exibicionista, como o voyeur não pode prescindir da presença do outro sobre quem deve exercer o impacto desejado. Daí advém seu permanente deslocamento." Ora, é o auteur quem autoriza que seja espiado, e é ele que pode (ou não) desorientar, desmontar o olhar voyeurístico do making of. Se não o faz é porque o que se instaura na relação entre as instâncias diretivas está mediado pela dimensão do desejo de ser visto, de ser espiado. Ou seja, o auteur se realiza por meio do voyeurismo alheio. Pois, “[...] no exibicionismo, o que é visado pelo sujeito é o que se realiza no outro. A visada verdadeira do desejo, é o outro, enquanto que forçado, para além de sua implicação em cena." (LACAN, 1988, p. 173).

Nesse sentido, tanto os depoimentos de Ridley Scott quanto os da equipe (desde roteirista, produtor, diretores de arte, designers de set, até o elenco) referenciam a figura do auteur como aquele no controle da obra. 0 exibicionista é tocado pelo deslumbramento e fabrica êxtases, produzindo um sentido que não necessariamente está ali. Estou me referindo aqui ao exibicionismo de sua persona enquanto artista, de sua obra e relevância para a história do cinema. Esse exibicionismo, no entanto, existe em função de um olhar voyeurístico que é sistematicamente hegemônico no campo do making of. Bourdieu (1996a) aponta que o valor da obra de arte como fetiche se dá pelo próprio campo de produção ao produzir a crença no poder criador do artista. Além disso, Bakhtin (2006) assinala que a compreensão dos signos, ou ainda, dos enunciados se dá de acordo com o contexto em que os mesmos tomam forma e esse contexto é sempre social. Ou seja, identifico um movimento dentro do campo que conduz e direciona a enunciação dos diretores do making of a fim da manutenção de uma dada ordem que valoriza o cinema ficcional e os auteurs.

Por outro lado, em Burden of Dreams, a autoria de Werner Herzog é delimitada desde o começo por meio da narração em voz over que o localiza enquanto diretor do filme Fitzcarraldo e, além disso, situa as dificuldades que o mesmo enfrentou durante a produção. 
Do dialogismo aos sentidos da dupla autoria nos making ofs documentários

A realização de Fitzcarraldo se torna, ao longo do MDoc, uma questão crucial e subjetiva para Werner Herzog, que usa o espaço de seus depoimentos para a câmera como forma de exposição de suas intenções, suas limitações, seus questionamentos. É justamente no uso desse espaço, com um nível de performance de si, que temos a corroboração do controle autoral de Herzog sobre o filme. Diferentemente de Dangerous Days e de outros MDocs, em Burden of dreams não temos acesso a depoimentos de membros da equipe ou de produtores, o que instaura um discurso de autonomia do diretor auteur com relação a sua obra de modo mais contundente. 0 status artístico da obra está associado ao próprio diretor e sua trajetória no cinema novo alemão. A sensação é de que Herzog é o indivíduo por trás de toda a criação do filme e que as poucas pessoas da equipe que aparecem em algumas cenas estão ali como meros assistentes. A voz da autoria do filme Fitzcarraldo é concedida a Herzog e não há questionamentos acerca disso.

No que concerne à figura de Les Blank, ao produzir e dirigir Burden of Dreams em 1982, concomitantemente à realização do filme Fiztcarraldo, de Werner Herzog, observo a construção de uma câmera que perambula pelo set. 0 modo de olhar de Les Blank não é simplesmente o de alguém que se faz presente na manipulação da câmera, mas trata-se de um olhar atento aos arredores. Seu foco não é, necessariamente, o filme do auteur sendo feito, mas a relação que advém dessa produção com os indígenas nativos do lugar em que estão filmando. Nesse sentido, Les Blank enquanto sujeito da câmera designa uma relação de olhar com o mundo ao redor do filme. A condição de produção do MDoc não é o único fator que permite essa abertura, mas o fato de que a posição que Les Blank ocupa advém de legitimação no campo do documentário e é homóloga a de Herzog no campo do cinema ficcional. Isto é, ambos compartilham o reconhecimento enquanto autores nos seus devidos campos de realização. Isso se traduz igualmente nas imagens de Les Blank ao entrevistar Herzog. Em diferentes momentos Herzog fala para a câmera e sua posição dentro do quadro é descentralizada. Ou seja, Les Blank constrói o enquadramento de modo a inserir Herzog no ambiente, diminuindo em alguns momentos, portanto, o sentido de controle que o mesmo tem sobre a obra. Em outras palavras, trata-se de enunciar um auteur não idealizado, produto da relação com o espaço que habita. A relação que se estabelece sob essa lógica circunscreve modos de enunciar que permite a Les Blank uma autonomia sobre seu making of documentário.

Há que considerar também um comentário de Herzog para o The Guardian acerca dessa independência do making of com relação ao filme - do mesmo modo que se inscreve enquanto dispositivo legitimador da autoria de Les Blank: 
Burden of Dreams não tinha nada a ver com a gravação daquele filme estranho. Era uma perspectiva justificável. Para Les, o que os índios nativos estavam cozinhando era muito mais importante do que o que estávamos fazendo. Ele criou seu próprio pequeno universo. Se Burden of Dreams tivesse sido apenas o making of de Fitzcarraldo então teria sido ruim. Ele tinha o talento para identificar os momentos significativos. (WERNER HERZOG, 2015, n.p., tradução nossa)

A configuração dos enunciados de Les Blank não se parece com o que vimos em Lauzirika. Diferentemente desse, aquele transforma a experiência do MDoc numa travessia exploratória, acometendo uma espécie de descentramento, sem um elemento fixo absoluto para tomar como objeto de desejo ou do discurso. Nesse sentido, identifico em Les Blank uma postura que dialoga com a figura do flâneur, elaborada por Charles Baudelaire. Em Baudelaire (BENJAMIN, 2000), a atividade errante do flâneur desponta como uma atitude de transgressão ao status quo vigente da primeira metade do século XX. De acordo com Renato Ortiz (2000), o flâneur de Benjamin é a tradução do espírito de mobilidade inaugurado pela modernidade. Assim,

O homem que se desloca no meio da multidão o faz impulsionado por sua curiosidade intelectual, ele deliberadamente toma a decisão de conhecer, de escolher os caminhos, para apreender, como uma máquina fotográfica, os pequenos detalhes da vida cotidiana. (ORTIZ, 2000, p. 20).

Les Blank, enquanto sujeito-da-câmera, lança esse olhar que busca, por um lado apreender os meandros do espaço criativo/produtivo com suas diferentes maneiras de fazer cinema e, de outro, captar e/ou construir as contradições que permeiam o auteur. David Frisby (19947 apud SILVEIRA, 2002) elucida a flânerie (a atividade de flanar) como uma forma de olhar, de acordo com o autor:

Flânerie, em outras palavras, pode ser associada com uma forma de olhar, de observar (pessoas, tipos sociais, contextos sociais e constelações); uma forma de ler a cidade e sua população (suas imagens espaciais, sua arquitetura, suas configurações humanas); e uma forma de ler textos escritos (no caso de Benjamin, tanto a cidade quanto o século XIX - como textos e de textos sobre a cidade, mesmo textos como labirintos urbanos). O flâneur, e a atividade da flânerie, é também associado, no trabalho de Benjamin, não meramente à observação e à leitura, mas também à produção - à produção de tipos distintivos de textos. 0 flâneur pode, portanto, ser mais do que simplesmente um observador, ou mesmo um

7 FRISBY, David. The Flâneur in Social Theory. In: KEITH, Tester (org.). The Flâneur. London: Routledge, 1994. Apud Silveira (2002). 
decifrador, ele pode ser também um produtor. Assim, o flâneur como produtor de textos deveria ser explorado (FRISBY, 1994 apud SILVEIRA, 2002, p. 18).

Podemos ler essa produção flâneur a partir do trabalho enunciativo da câmera no MDoc, que vaga e nos dá a ver a paisagem na qual se criam os filmes. Burden of Dreams se constrói enquanto um registro de fragmentos que desvelam os sentidos de uma produção em que os coadjuvantes (os habitantes indígenas da região amazônica) também se tornam objeto. Através dos depoimentos de Herzog, mas em meio a esse registro, somos convidados a adentrar no universo de Fitzcarraldo.

0 que desponta como um posicionamento relativo à autoria flâneur é a figura dândi da autoria de Werner Herzog. O dandismo é entendido aqui a partir de Baudelaire (2013), donde destaco a compreensão do conceito numa espécie de rebeldia, uma oposição ao sistema moral da consciência burguesa. A excentricidade, a frivolidade e o louvor à elegância constituem características do dândi que, por vezes, impedem que se compreenda a ambiguidade presente na sua forma de ser. Rodgers (2012 ${ }^{8}$ apud BARBOSA, 2015, p.5) questiona: "O dândi, superficial em seu orgulho de pavão mas profundo em seu desafio ao mundo comercial, permanece um enigma. É ele um aristocrata ou um democrata? Ou um aristocrata e um democrata?". É possível vislumbrar, não apenas nos depoimentos de Werner Herzog, mas também na trajetória social dele, o elemento ambíguo que o localiza entre a elite estética da arte e certa atitude revolucionária. De acordo com Rodgers:

Ao invés de fugir do mundo industrial democrático, como a maioria dos românticos fez, o dândi o confrontou. Ele tentou recriar uma elite prérevolucionária - uma elite estética - num mundo pós-revolucionário, saindo aos bulevares para impressionar e inspirar. (RODGERS, 2012 apud BARBOSA, 2015, p. 5).

Alinho-me ao pensamento de Barbosa (2015) que considera possível pensar o dandismo enquanto uma característica das obras, para além do modo de ser dândi dos autores delas. Conforme o autor, "Se o dandismo é uma relação com as coisas do mundo inspirada no modo de vida do dândi, então é uma atitude estética que pode ser identificada na forma de uma obra de arte e, portanto, na mise-en-scène de um filme." (BARBOSA, 2015, p. 7, grifo do autor). Tal abertura nos permitiria considerar, portanto, o dândi não apenas na postura do auteur Werner Herzog, mas também nos seus filmes. Diante dessa possibilidade, 
Do dialogismo aos sentidos da dupla autoria nos making ofs documentários

considero relevante analisar o aspecto da mise-en-scène $e^{9}$ no MDoc que registra o auteur quando o mesmo se coloca para a câmera. Ao longo de Burden of Dreams, alguns depoimentos de Herzog explicitam uma zona passível de identificação com a figura do dândi, em que ora parece atingir uma sensibilidade transformadora, ora manifesta um radicalismo frívolo:

E eu acho que algumas coisas não devem ser contadas ou calculadas em forma de dinheiro. 0 que é mais importante para os nativos aqui é que esta terra, que não tem escritura ainda vai pertencer a eles após termos concluído o filme. Esforçar-se para que eles tenham a escritura desta terra, por todo este território, que nem colonizadores ou companhias de petróleo ou madeireiros possam explorar e tirar deles, isto é algo decisivo. Não são apenas os meus sonhos. Minha crença é de que todos estes sonhos são seus também. E a única distinção entre eu e você é que eu posso articulá-los. E isso é disso que a poesia, pintura, literatura ou cinema tratam. Simples assim. E eu faço filmes porque eu não aprendi outra coisa. E eu sei que posso fazê-los até um certo ponto. E é minha obrigação. Porque isso pode ser a crônica interior do que nós somos. E temos de nos articular de alguma maneira, senão nós seríamos vacas no pasto (BURDEN OF DREAMS, 1982).

O espectro desse quadro põe em relevância o sentido da dupla autoria flâneur dândi agenciada no MDoc Burden of Dreams enquanto condição possível devido a: (1) o campo do making of começava a ser pensado e desenvolvido em consonância com a tecnologia a partir da década de 1990 (VHS e laserdics), de modo que o habitus dos produtores ainda não era capaz de moldar todas as produções; (2) a trajetória do diretor Les Blank a circunscreve no campo do documentário, o que implica que as determinações do campo do making of são (ou podem ser) reestruturadas de acordo com as tomadas de posição empreendidas por ele; (3) o auteur reconhece o trabalho autoral daquele que o enuncia, o que diz muito do modo constitutivo da relação flâneur - dândi como experiência existencial de uma subjetividade fruidora.

Em última instância, o que se depreende do espaço da autoria nos MDocs analisados é que em Dangerous Days trata-se de uma autoria que constrói seu ponto de vista por meio da manipulação da montagem discursiva de entrevistas e imagens de arquivo, buscando iluminar o controle do auteur no campo do cinema ficcional. 0 que constitui, ao meu ver, uma relação que contribui para a manutenção das sombras da autoria do campo do making of. 0 mesmo se coloca enquanto voyeur-arqueólogo, que espia ao remontar a história de outrem, que, por sua vez, se prostra diante da câmera transformando simbolicamente a si

9 Estou tomando o conceito de mise-en-scène a partir de Jacques Aumont (2003), cuja definição designa a noção da cena como o espaço dramático sobre o que se desenrola uma determinada ação dramática com certa unidade. 
Do dialogismo aos sentidos da dupla autoria nos making ofs documentários

mesmo e sua obra enquanto objeto do discurso e de desejo. Enquanto isso, em Burden of Dreams, a presença de um sujeito-da-câmera (que se identifica com o diretor que o filma), para além das manipulações na montagem, incorpora um nível de subjetividade que lança as bases para tomadas de posição que tendem a transformar o modo de enunciar e olhar o Outro no campo do making of. Institui-se um tipo de relação na qual o diretor do making of percorre os caminhos possíveis de uma autoria tal qual um flâneur-etnógrafo, cujas práticas remetem a uma mobilidade pelos meandros do fazer cinematográfico atenta aos arredores e às aspirações dandescas dos auteurs por detrás das produções. Portanto, vislumbro nessa relação de dupla autoria flâneur-dândi a possibilidade de reconhecimento e legitimação da autoria no making of, em virtude de seu protagonismo se evidenciar tanto pelos agentes e instituições do campo quanto na própria estrutura formal e discursiva do making of documentário.

Assim, o espaço da autoria se expressa enquanto uma disposição do campo do making of e aponta para uma ampliação do debate acerca do posicionamento de um cineasta. Ainda que a própria existência do MDoc seja sancionada pelo(s) estúdio(s) de produção dos filmes, ressalto que para mostrar o que mostra e dizer o que diz, o making of documentário o faz de uma maneira específica, por meio do olhar de um diretor. Alçar esse diretor a ocupação de um espaço autoral não significa compreender sua atuação no âmbito da inventividade e originalidade associadas ao gênio criador. Do contrário, significa localizar sua autoria como uma circunstância tornada possível por condições específicas do campo desde as posições ocupadas pelo diretor, suas filiações, atitudes, discursos, até as suas propostas estético-expressivas. E, além disso, significa encontrarmos marcas discursivas que enunciam diferentes posicionamentos. Esse encontro das instâncias diretivas no making of documentário é modulado, portanto, por uma noção de dupla autoria, manifestada, de um lado, pela trajetória social e, de outro lado, pela constituição de um dado discurso acerca do filme no espaço dos possíveis do campo.

\section{Referências}

AUMONT, Jacques; MARIE, Michel. Dicionário teórico e crítico de cinema. Campinas SP: Papirus, 2003.

BAKHTIN, Mikhail. Marxismo e filosofia da linguagem. 12. ed. São Paulo: HUCITEC, 2006. 
Do dialogismo aos sentidos da dupla autoria nos making ofs documentários

BARBOSA, André Antônio. 0 dandismo de dois filmes contemporâneos. In: ENCONTRO DA ASSOCIAÇÃO NACIONAL DOS PROGRAMAS DE PÓS-GRADUAÇÃO EM COMUNICAÇÃO, 24., 2015, Brasília. Anais [...]. Brasília: UnB, 2015. p. 1-19.

BAUDELAIRE, Charles. O Dândi. In: TADEU, Tomaz (org.). Manual do Dândi: a vida com estilo/ Honoré de Balzac, Charles de Baudelaire, Barbey d'Aurevilly. Belo Horizonte:

Autêntica, 2013.

BENJAMIN, Walter. A modernidade e os modernos. Rio de Janeiro: Tempo Brasileiro, 2000.

BOURDIEU, Pierre. As regras da arte: gênese e estrutura do campo literário. São Paulo: Companhia das Letras, 1996a.

BOURDIEU, Pierre. Razões práticas: sobre a teoria da ação. 7. ed. Campinas: Papirus, 1996b.

BOURDIEU, Pierre. 0 senso prático. 3. ed. Petrópolis: Vozes, 2013.

BURDEN OF DREAMS. Making of do filme Fitzcarraldo. Direção: Les Blank. Los Angeles: Flower Films, 1982, 16mm (95 min). Produzido por: Flower Films, Independent Documentary Fund, The National Endowment for the Arts Ford Foundation, Corporation for Public Broadcasting (CPB), Public Television Stations, SDR Fernsehen (as S.D.R. Television). Disponível em DVD na Edição Especial do filme Fitzcarraldo.

CALDWELL, John T. Production culture: industrial reflexivity and critical practice in film and television. Durham: Duke University Press, 2008.

CUNHA, Tito Cardoso e. Teoria dos cineastas versus teoria do autor. In: BAGGIO, Eduardo Tulio et al. (org.). Revisitar a teoria do cinema: teoria dos cineastas. Covilhã: LabCom UBI, 2017. v. 3.

DANGEROUS DAYS: Making Blade Runner. Direção: Charles de Lauzirika. Los Angeles: Warner Brothers, 2007, (214 min). Produzido por Warner Home Video, Blade Runner Partnership, Lauzirika Motion Picture Company. Disponível em DVD/Blu-ray Edição Especial do filme Blade Runner.

HANSEN, Miriam. Benjamin, cinema e experiência: a flor azul na terra da tecnologia. In: BENJAMIN, Walter [et al.] Benjamin e a obra de arte - técnica, imagem, percepção. Rio de Janeiro: Contraponto, 2012.

LACAN, Jacques. 0 seminário: livro 11: quatro conceitos fundamentais em psicanálise. Rio de Janeiro: Jorge Zahar Editora, 1988.

LAUZIRIKA, Charles de. Charles De Lauzirika Interview. [Entrevista cedida ao] Alien vs Predator Galaxy. Entrevistador: Aaron Percival. 29 Nov. 2016. Disponível em: http://www.avpgalaxy.net/website/interviews/charles-de-lauzirika/?page1. Acesso em: 5 de out. 2015.

LES BLANK obituary. The Guardian, [s. l.], [2016]. Disponível em: http://www.theguardian.com/film/2013/apr/12/les-blank-dies-documentary-music. Acesso em: 5 de fev. 2016. 
Do dialogismo aos sentidos da dupla autoria nos making ofs documentários

LES BLANK and Werner Herzog: strange dreams and sole food. The Guardian, [s. l.], [2015]. Disponível em: http://www.theguardian.com/film/2013/apr/12/les-blank-werner-herzog. Acesso em: 5 de dez. 2015.

LUCCHESI, Ivo. Do flâneur ao voyeur: a crise da(s) modernidade(s). Revista Tempo Brasileiro (abr-jun), número 141: Rio de Janeiro, 2000.

MACHADO, Irene. Os gêneros e a ciência dialógica do texto. In: FARACCO, Carlos Alberto (org.). Diálogos com Bakhtin. Curitiba: UFPR, 2007.

NICHOLS, Bill. Introdução ao documentário. São Paulo: Papirus, 2005.

ORTIZ, Renato. Walter Benjamin e Paris: individualidade e trabalho intelectual. Tempo Social, São Paulo, v. 12, n. 1, p. 11-28, maio 2000.

SILVEIRA, Fabrício Lopes. 0 olhar etnográfico de Walter Benjamin. In: CONGRESSO BRASILEIRO DE CIÊNCIAS DA COMUNICAÇ̃̃O, 25., 2002, Salvador. Anais [...]. 2002. Salvador: [s. n.] 2002.

WOLF, Janet. La producción social del arte. Madrid: Ediciones ISTMO, 1997.

\title{
From dialogism to the senses of double authorship in the making of documentaries
}

\begin{abstract}
The proposal of this work discusses the encounter between the authorial directive instances in the audiovisual expression of the making of documentary. We take as theoretical horizon the social construction of authorship proposed by Pierre Bourdieu (1996a, 2013) and the notions of positioning and dialogism worked by Bakhtin (2006), in order to explain alternative ways for the author's theories in cinema. Starting from a dialogical relationship with the film and its respective auteur, we analyze the discourse of making of documentaries in the configuration of the author's space by its directors, Les Blank and Charles de Lauzirika, whose statements express meanings of a double authorship: voyeur-exhibitionist and flâneur -dandy.
\end{abstract}

\section{Keywords}

Authorship. Making of documentary. Field. Dialogism. Discourse. 
Do dialogismo aos sentidos da dupla autoria nos making ofs documentários

Recebido em 13/05/2019

Aceito em 17/06/2019 